\title{
Prof. Hiroyuki Nakamura: accelerator-based BNCT will be chosen as a primary therapy for early stage cancer
}

Received: 15 November 2018; Accepted: 08 December 2018; Published: 14 December 2018.

doi: $10.21037 /$ tro.2018.12.06

View this article at: http://dx.doi.org/10.21037/tro.2018.12.06

\section{Editor's note}

The 18th International Congress on Neutron Capture Therapy was held successfully at the Chang Yung-Fa International Convention Center in Taipei, Taiwan from October 28th to November 2nd, 2018. The theme of the 18th Congress is "Precision Therapy, Beautiful Tomorrow-We Here, We Care". This congress gathered international clinicians and researchers from industry and academia to feature their findings and generate new thoughts and discoveries related to neutron capture therapy. The key areas included the latest development in accelerator-based neutron sources, the next generation of boron-10 delivery agents, as well as the latest results in chemical, biological and clinical research.

At this congress, Therapeutic Radiology and Oncology (TRO) had the great honor to invite Prof. Hiroyuki Nakamura from the Tokyo Institute of Technology to have an exclusive interview with us, allowing our readers to know more about the research of albumin-based boron delivery and the future of boron neutron capture therapy (BNCT) (Figure 1).

\section{Expert introduction}

Prof. Nakamura (Figure 2) has been the President of the Japanese Society of Neutron Capture Therapy since 2015. He received his $\mathrm{PhD}$ from Tohoku University under the supervision of Prof. Yoshinori Yamamoto in 1996. He was an assistant professor at Kyushu University [1995-1997] and at Tohoku University [1997-2002]. He worked with Prof. Dennis Curran at the University of Pittsburgh [2000-2001]. In 2002, he was appointed as an associate professor at Gakushuin University and promoted to professor in 2006. In 2013, he was appointed as a professor at Tokyo Institute of Technology. He is a visiting professor at Dalian University of Science and Technology since 2017.

Prof. Nakamura received the Chemical Society of Japan Award for Young Chemists in 1999 and the Japanese Society

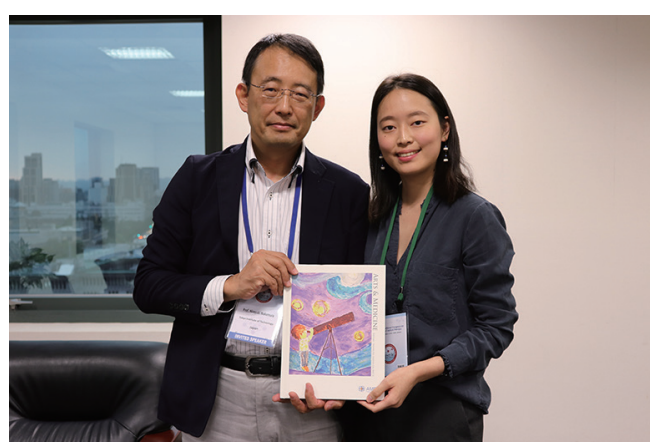

Figure 1 Prof. Hiroyuki Nakamura with science editor from Therapeutic Radiology and Oncology (TRO).

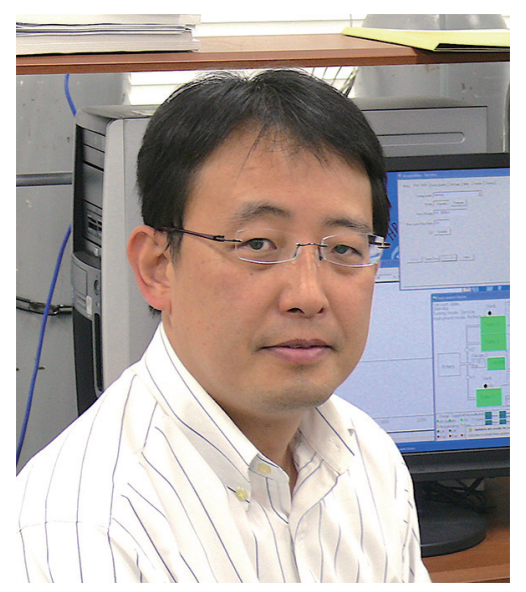

Figure 2 Prof. Hiroyuki Nakamura, Laboratory for Chemistry and Life Science (CLS), Institute of Innovative Research, Tokyo Institute of Technology, Yokohama, Japan.

of Molecular Targeting Therapy of Cancer Award in 2007. His research interests include development of new synthetic methodology, boron-based medicinal chemistry, chemical biology for target protein identification and modification, and neutron capture therapy. 


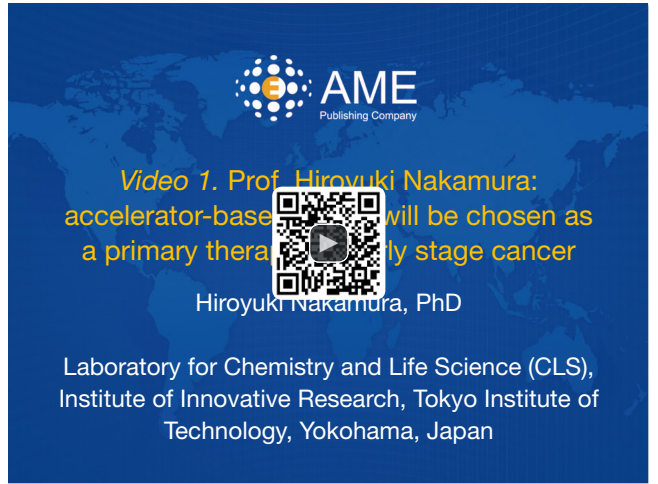

Figure 3 Prof. Hiroyuki Nakamura: accelerator-based BNCT will be chosen as a primary therapy for early stage cancer (1). BNCT, boron neutron capture therapy.

Available online: http://www.asvide.com/article/view/28897

\section{Interview (Figure 3)}

TRO: Could you please briefly explain the mechanism of your current study "Albumin-Based Boron Delivery"?

Prof. Nakamura: In 1986, Dr. Matsumura and Dr. Maeda found that albumin accumulates in tumor cells and this is due to the abnormal architecture of the tumor blood vessel, this phenomenon is called the enhanced permeability and retention effect (EPR). Since we know that albumin accumulates in tumor tissues which proves the critical role of nanoparticle size in boron delivery research, we decided to utilize this phenomenon to design our boron delivery system.

\section{TRO: What are the current clinical applications of your} study or more broadly BNCT in Asia?

Prof. Nakamura: In fact, my boron delivery system has not yet applied for clinical trials. But L-BPA, which is an amino acid derivative formulated with a sorbitol complex, was under phase II clinical trials for brain tumors and head and neck cancers in Japan. The phase II clinical trial has finished and we are now preparing the approval review request which hopefully will be submitted next autumn.

TRO: What are Fapan's advantages compared to other Asian countries on BNCT research? And what are the critical issues that are faced or should be addressed in this field?

Prof. Nakamura: The advantages can probably be summarized into three aspects. First, Japan has a long history of using BNCT for various experiments and treatments. The second advantage is that Japan has strong organizations, such as the Japan Society of Neuron Capture Therapy. We always exchange ideas and opinions and also have discussions with each other very frequently through these organizations. The last advantage is that we have the only accelerator for BNCT clinical use in the world. These three aspects are probably the most important advantages of our country compared to other Asian countries.

I think the most critical aspect of BNCT research that should be addressed is patient evaluation. Patients can be evaluated for their suitability for BNCT before treatment by using FBPA-PET imaging, which means we can avoid patients who are not suitable for BNCT. This kind of evaluation is very important and is also a key factor to the success of BNCT in Japan.

TRO: As the president of the Fapanese Society of Neutron Capture Therapy, what do you see as the future of BNCT research in the coming ten years?

Prof. Nakamura: In the coming ten years, I think accelerator-based BNCT will be approved as one of the conventional radiotherapy options so that people, including medical doctors, will realize how powerful BNCT is and BNCT will be chosen as a primary therapy for early stage cancer.

TRO: What do you see as the future of collaboration between Taiwan and Japan on this research?

Prof. Nakamura: I believe Taiwan and Japan will have stronger and closer collaborations because I think Taiwan will install accelerator-based BNCT facilities in the future. Even now, we have many meetings and conferences dedicated to BNCT research and I can foresee that we will have even more stronger connections between Taiwan and Japan to work on more advanced BNCT research together.

TRO: With many years devoted to BNCT research, could you give some advice to young researchers studying or working in this field?

Prof. Nakamura: BNCT uses two important factors, neutron and boron compounds. We used to obtain neutrons from reactors but now we can obtain neutrons from accelerators so we can proceed with BNCT in the hospital. The other critical issue is related to boron compounds. 
Until now, we still only have one boron compound used clinically and this boron compound was synthesized 60 to 70 years ago, so we have a lot of possibilities to improve BNCT through boron compounds. So maybe new researchers, especially chemists, should consider how to design boron compounds that are suitable for BNCT.

\section{Acknowledgments}

Funding: None.

\section{Footnote}

Provenance and Peer Review: This article was commissioned by the editorial office, Therapeutic Radiology and Oncology for the series "Meet the Professor". The article did not undergo external peer review.

Conflicts of Interest: The author has completed the ICMJE uniform disclosure form (available at http://dx.doi. org/10.21037/tro.2018.12.06). The series "Meet the Professor" was commissioned by the editorial office without any funding or sponsorship. Tan-Lun Yu reports that she is a full-time employee of AME publishing company (publisher of the journal). The author has no other conflicts of interest

doi: $10.21037 /$ tro.2018.12.06

Cite this article as: Yu TL. Prof. Hiroyuki Nakamura: accelerator-based BNCT will be chosen as a primary therapy for early stage cancer. Ther Radiol Oncol 2018;2:63. to declare.

Ethical Statement: The author is accountable for all aspects of the work in ensuring that questions related to the accuracy or integrity of any part of the work are appropriately investigated and resolved.

Open Access Statement: This is an Open Access article distributed in accordance with the Creative Commons Attribution-NonCommercial-NoDerivs 4.0 International License (CC BY-NC-ND 4.0), which permits the noncommercial replication and distribution of the article with the strict proviso that no changes or edits are made and the original work is properly cited (including links to both the formal publication through the relevant DOI and the license). See: https://creativecommons.org/licenses/by-nc-nd/4.0/.

\section{References}

1. Yu TL. Prof. Hiroyuki Nakamura: accelerator-based BNCT will be chosen as a primary therapy for early stage cancer. Asvide 2018;5:910. Available online: http://www.asvide.com/ article/view/28897

(Science Editor: Tan-Lun Yu, TRO, tro@amegroups.com) 